\title{
DESEMPENHO DE CULTIVARES DE SOJA EM PALHADA DE CANA-DE-AÇÚCAR NO NOROESTE PAULISTA
}

ISSUE DOI: $10.3738 /$ nucleus.v0i0.907

\author{
BORGES, Wander Luis Barbosa ${ }^{1}$; \\ MATEUS, Gustavo Pavan'; \\ FREITAS, Rogério Soares de ${ }^{1}$; \\ HIPÓLITO, Jorge Luiz'; \\ TOKUDA, Flávio Sueo \\ GASPARINO, Adriano Custódio ${ }^{4}$; \\ TOMAZINI, Nicola Roberto; \\ CAZENTINI FILHO, Gerson
}

RESUMO: A prática de colheita de cana-de-açúcar sem a despalha a fogo pode contribuir significativamente para a melhoria da fertilidade do solo, através da ação dos microrganismos do solo disponibilizando esses nutrientes para a absorção pelas plantas. O trabalho foi desenvolvido em Araçatuba, SP, durante a safra de 2011/12, e em Araçatuba, SP e Américo de Campos, SP, na safra 2012/13, e teve por objetivo avaliar o desempenho de diferentes cultivares de soja, cultivadas no sistema de semeadura direta sobre a palhada de cana-de-açúcar, nas condições edafoclimáticas do Noroeste Paulista. O delineamento experimental utilizado foi o de blocos casualizados com três repetições e cinco tratamentos (cultivares de soja), sendo as parcelas compostas por vinte e uma linhas de $50 \mathrm{~m}$ de comprimento cada, em Araçatuba, SP, nos dois anos de estudo, e por sete linhas de $50 \mathrm{~m}$ de comprimento cada, em Américo de Campos, SP. Os tratamentos constaram das seguintes cultivares na safra 2011/12: P 98Y11 RR; CD 219 RR; M-Soy 7908 RR; BRS Valiosa RR e SYN 9078 RR, e das seguintes cultivares na safra 2012/13: P 98Y11 RR; NA 7490 RR; M-Soy 7908 RR; BRS Valiosa RR e SYN 9078 RR. As diferentes cultivares de soja avaliadas apresentaram bom desenvolvimento vegetativo e boas produtividades de grãos na Região Noroeste Paulista.

Palavras-chave: Glycine max (L.) Merrill, Saccharum spp., Estabilidade de produção, Características agronômicas.

\section{PERFORMANCE OF SOYBEAN CULTIVARS ON STRAW SUGARCANE IN THE NORTHWEST OF SÃO PAULO STATE, BRAZIL}

\begin{abstract}
SUMMARY: The practice of harvesting cane sugar without straw removal by fire can significantly contribute to the improvement of soil fertility, through the activity of soil microorganisms providing these nutrients for plant uptake. The study was conducted in Araçatuba, SP, Brazil, during crop years 2011/12, and Araçatuba, SP, Brazil, and Américo de Campos, SP, Brazil, in 2012/13 and aimed to evaluate the performance of different soybean cultivars grown in no till system on straw cane sugar, at conditions of Northwest of São Paulo State. The experimental design was a randomized block with three replications and five treatments (soybean cultivars), and the plots consist of twenty-one lines $50 \mathrm{~m}$ long in Araçatuba, SP, Brazil, in the two years of study, and seven rows $50 \mathrm{~m}$ long in Américo de Campos, SP, Brazil. Treatments consisted of the following cultivars in 2011/12 season: P 98Y11 RR, CD 219 RR, M-Soy 7908 RR, BRS Valiosa RR and SYN 9078 RR and the following cultivars in 2012/13: P 98Y11 RR, NA 7490 RR, M-Soy 7908 RR, BRS Valiosa RR and SYN 9078 RR. The different soybean cultivars evaluated showed good vegetative growth and good grain yields in the Northwest of São Paulo State.
\end{abstract}

Keywords: Glycine max (L.) Merrill, Production stability, Production stability, Agronomic characteristics.

\section{INTRODUÇÃO}

Durante vários anos a colheita da cana-de-açúcar foi realizada manualmente com queimada prévia da palha, visando aumentar o rendimento da operação. Esse sistema de colheita reduz a quantidade de

\footnotetext{
${ }^{1}$ Pesquisador Científico, Dr. - APTA - PRDTA Noroeste Paulista, Votuporanga, SP;

${ }^{2}$ Pesquisador Científico, Dr. - APTA - PRDTA Extremo Oeste, Andradina, SP;

${ }^{3}$ Assistente Agropecuário - CATI - EDR Araçatuba, Araçatuba, SP;

${ }^{4}$ Assistente Agropecuário - CATI - EDR Votuporanga, Votuporanga, SP;

${ }^{5}$ Assistente Agropecuário - CATI - DSMM - NPS, Araçatuba, SP;

${ }^{6}$ Assistente Agropecuário - CATI - DSMM - NPS, Fernandópolis, SP.
} 
material orgânico sobre o solo e contribui para o aumento da concentração de gás carbônico na atmosfera, contribuindo com o efeito estufa e para a diminuição do teor de matéria orgânica no solo (SOUZA et al., 2005).

No entanto, a Lei Estadual 11.241 estabelece para 2021 a extinção da queima da palha como método de pré-colheita da cana-de-açúcar na maior parte da área cultivada do Estado de São Paulo. O Protocolo Etanol Verde, iniciativa do governo estadual e do setor sucroenergético, antecipa esse prazo para 2014 e prevê a concessão anual de um certificado de conformidade aos produtores que adotarem boas práticas de manejo (CANASAT, 2013).

Qualquer mudança no sistema produtivo promove, em maior ou menor grau, alterações nas condições microclimáticas (KUVA, 2006). De acordo com Staben et al. (1997), a degradação do solo pelo cultivo é manifestada por processos erosivos, redução da matéria orgânica, perda de nutrientes, compactação do solo, redução de populações microbianas, de atividades enzimáticas e pH. Assim, tornase imprescindível a adoção de práticas agrícolas sustentáveis, que causem menores danos ao ambiente em que estão inseridas, como também estudos sobre o efeito que diferentes sistemas causam ao ambiente de produção, definindo assim a melhor estratégia de uso e manejo, buscando sempre a melhoria da qualidade de vida humana, animal e vegetal (PAREDES JUNIOR, 2012).

A prática de colheita de cana-de-açúcar sem a despalha a fogo pode contribuir significativamente para a melhoria da fertilidade do solo, através da ação dos microrganismos do solo disponibilizando esses nutrientes para a absorção pelas plantas (ABRAMO FILHO et al., 1993; TRIVELIN et al., 1996).

O sistema de semeadura direta em áreas com palhada de cana-de-açúcar teve seu início em meados da década de 80, com a avaliação e adaptabilidade de variedades de culturas utilizadas como rotação quando no período de reforma dos canaviais. Na década de 90, com as dificuldades do setor sucroalcooleiro e com o aumento progressivo do corte mecanizado de cana crua intensificaram-se os estudos para diminuição dos custos operacionais do preparo do solo e o aproveitamento racional da grande quantidade de palha da cultura anterior, que dependendo da variedade, varia entre 9 a 15 toneladas por hectare (NOGUEIRA, 2012).

Tasso Junior (2000) estabeleceu algumas vantagens do sistema de semeadura direta sobre a palhada de cana-de-açúcar: maior vigor, velocidade de crescimento e desenvolvimento da planta; maior resistência a períodos veranicos; menor ataque de pragas; na cultura da soja, maior velocidade dos efeitos da inoculação; conservação da umidade; controle de erosão e cobertura ao solo; aumenta a capacidade de infiltração da água de chuva; estabiliza a temperatura do solo, favorecendo as propriedades biológicas do solo; auxilia o controle de plantas invasoras por suspensão ou alelopatia; reduz a compactação, devido o menor trânsito de máquinas na lavoura.

Tradicionalmente, no período de renovação são cultivadas leguminosas adubos verdes ou comerciais, com destaque para soja que contribui para amortizar cerca de $40 \%$ do custo de implantação do novo canavial. O uso de cultivares de soja RR pode contribuir sobremaneira para expandir a adoção do plantio direto, pois não há necessidade de esperar a rebrota da soqueira (entre 45 e 50 dias) para realizar a destruição química, além da maior praticidade e eficiência no controle de plantas daninhas de difícil controle (BOLONHEZI et al., 2008).

Finoto et al. (2012) avaliaram a produção de soja RR e ocorrência de plantas daninhas em áreas de reforma de cana crua com diferentes manejos na destruição da soqueira, e constataram que a semeadura direta de soja, no método de manejo já consagrado (dessecação prévia à semeadura), conferiu aumentos de $911 \mathrm{~kg} \mathrm{ha}^{-1}$ na produtividade de grãos em comparação ao preparo de solo convencional.

Por ser uma tecnologia recente, a produção de soja sobre a palhada de cana-de-açúcar, na renovação de canavial com colheita sem queima, tem gerado muitas dúvidas, principalmente com relação 
a cultivares recomendados para esta condição.

O presente trabalho teve por objetivo avaliar o desempenho de diferentes cultivares de soja, cultivadas no sistema de semeadura direta sobre a palhada de cana-de-açúcar, nas condições edafoclimáticas do Noroeste Paulista.

\section{MATERIAL E MÉTODOS}

Na safra 2011/12 o trabalho foi desenvolvido em Araçatuba, SP, e na safra 2012/13 em Araçatuba, SP e Américo de Campo, SP, com a semeadura da soja realizada mecanicamente, com semeadoras de grãos, em sistema de semeadura direta sobre a palhada da cana-de-açúcar colhida sem queima (cana crua), na renovação do canavial.

O delineamento experimental utilizado foi o de blocos casualizados com três repetições e cinco tratamentos (cultivares de soja), sendo as parcelas compostas por vinte e uma linhas de $50 \mathrm{~m}$ de comprimento cada, em Araçatuba, SP, nos dois anos de estudo, e por sete linhas de $50 \mathrm{~m}$ de comprimento cada, em Américo de Campos, SP.

\section{Safra 2011/12:}

A semeadura da soja foi realizada no dia 28 de novembro de 2011, utilizando-se as cultivares de soja: P98Y11 RR; CD 219 RR; M-Soy 7908 RR; BRS Valiosa RR e SYN 9078 RR.

Realizou-se a calagem e gessagem em pré-semeadura, a lanço sobre a palhada, com $1033 \mathrm{~kg} \mathrm{ha}^{-1}$ de calcário dolomítico e $1033 \mathrm{~kg} \mathrm{ha}^{-1}$ de gesso. Na adubação de semeadura utilizou-se $330 \mathrm{~kg} \mathrm{ha}^{-1}$ do adubo formulado 05-25-15.

\section{Safra 2012/13:}

A semeadura da soja foi realizada no dia 13 de novembro de 2012, em Araçatuba, SP e no dia 20 de dezembro de 2012, em Américo de Campos, SP, utilizando-se cinco cultivares de soja: P 98Y11 RR; NA 7490 RR; M-Soy 7908 RR; BRS Valiosa RR e SYN 9078 RR.

A cultivar CD 219 RR, utilizada na safra anterior, foi substituída pela NA 7490 RR, devido a dificuldade de aquisição de sementes.

Em Araçatuba, SP realizou-se a calagem e gessagem em pré-semeadura, a lanço sobre a palhada, com $1200 \mathrm{~kg} \mathrm{ha}^{-1}$ de calcário e $400 \mathrm{~kg} \mathrm{ha}^{-1}$ de gesso. Na adubação de semeadura utilizou-se $240 \mathrm{~kg} \mathrm{ha}^{-1}$ do adubo formulado 06-18-18, com 10\% S, 0,3\% B e 0,2\% de Zn. Foram utilizadas cinco doses de inoculante líquido para inoculação das sementes. $\mathrm{O}$ espaçamento utilizado foi o de $0,45 \mathrm{~m}$ e a densidade de semeadura variou de acordo com a recomendação pelos detentores de cada cultivar. A área total de cada parcela foi de $12,15 \mathrm{~m}$ de largura por $50 \mathrm{~m}$ de comprimento $\left(607,5 \mathrm{~m}^{2}\right)$.

Em Américo de Campos, SP realizou-se a calagem e gessagem em pré-semeadura, a lanço sobre a palhada, com $2000 \mathrm{~kg} \mathrm{ha}^{-1}$ de calcário e $1000 \mathrm{~kg} \mathrm{ha}^{-1}$ de gesso. Na adubação de semeadura utilizou-se 250 $\mathrm{kg} \mathrm{ha}^{-1}$ do adubo formulado 04-20-20. Foram utilizadas cinco doses de inoculante líquido para inoculação das sementes. O espaçamento utilizado foi o de $0,5 \mathrm{~m}$ e a densidade de semeadura variou de acordo com a recomendação pelos detentores de cada cultivar. A área total de cada parcela foi de 3,5 m de largura por $50 \mathrm{~m}$ de comprimento $\left(175 \mathrm{~m}^{2}\right)$.

Foi realizado o tratamento fitossanitário adequado para o bom desenvolvimento da cultura da soja nos dois locais, nos dois anos de estudo.

As densidades de semeadura utilizadas seguiram a recomendação dos detentores das cultivares. 
Na safra 2011/12, a amostragem do solo foi realizada no início de setembro de 2011, e na safra 2012/13, no início de outubro de 2012, nos dois locais, retirando-se amostras nas profundidades de 0-5, 520 e 20-40 cm, para análise dos teores de macronutrientes do solo, nas duas áreas. Os resultados encontram-se na Tabela 1.

Tabela 1. Resultados de análise de solo, em diferentes profundidades, em Araçatuba, SP, safra 2011/12, e em Araçatuba, SP e Américo de Campos, SP, safra 2012/13.

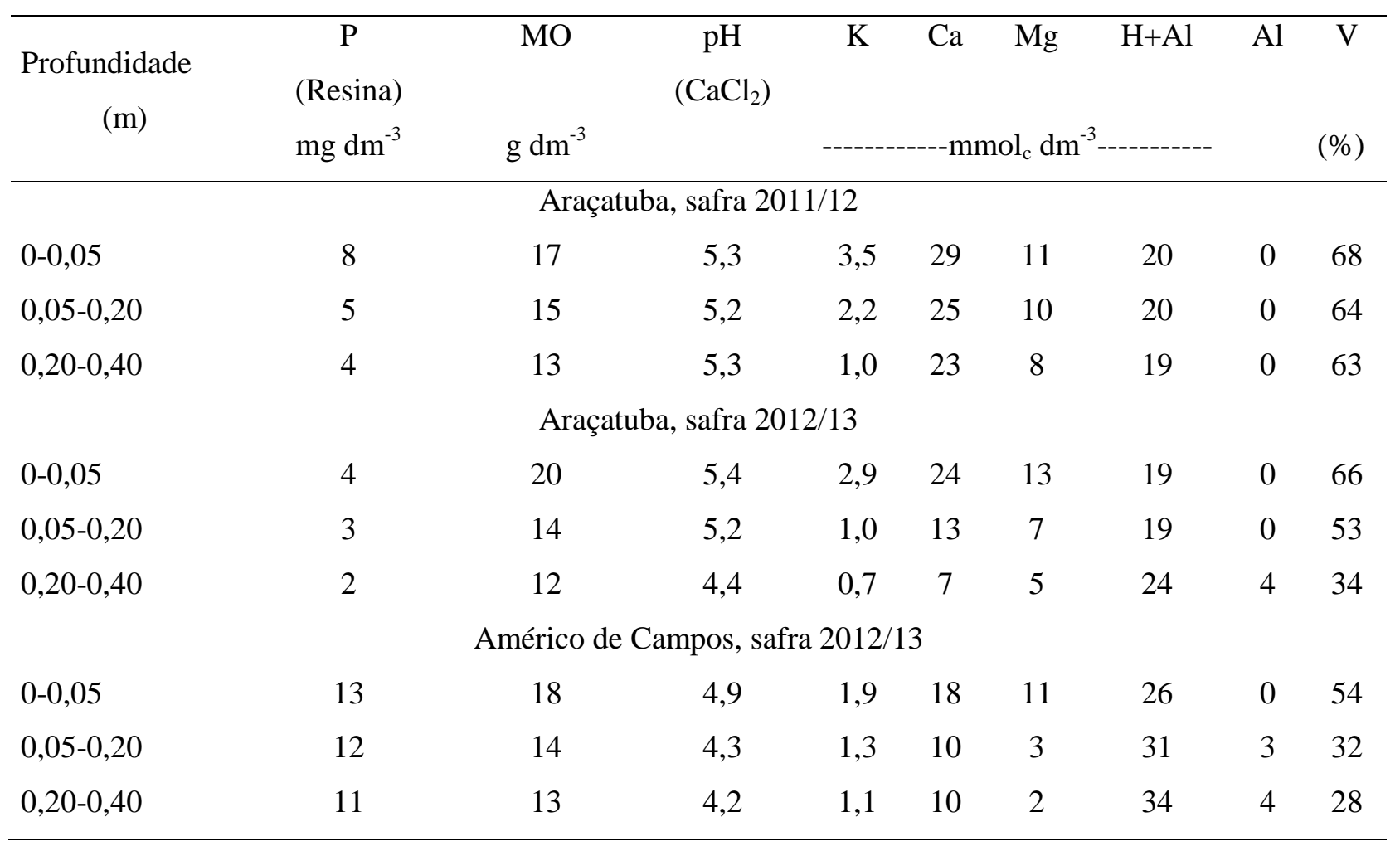

A amostragem do solo para fins de análise física do solo foi realizada no dia início de novembro de 2011, na safra 2011/12 e no início de outubro de 2012, na safra 2012/13. Foram avaliadas a densidade do solo, macro e microporosidade, retirando-se três amostras por parcela, nas profundidades de 0-5, 5-20 e 20-40 cm, e a resistência do solo a penetração, mediante o uso do Medidor Eletrônico de Compactação do Solo (penetroLOG). Os resultados encontram-se na Tabela 2 e nas Figuras 1, 2 e 3.

Tabela 2. Teores médios de macroporosidade $(\mathrm{M})$, microporosidade $(\mu)$, porosidade total $(\mathrm{PT})$ e densidade do solo (DS), em diferentes profundidades, em Araçatuba, SP, safra 2011/12, e em Araçatuba, SP e Américo de Campos, SP, safra 2012/13.

(Continua)

\begin{tabular}{|c|c|c|c|c|}
\hline \multirow{2}{*}{$\begin{array}{c}\text { Profundidade } \\
\text { (m) }\end{array}$} & M & $\mu$ & PT & DS \\
\hline & \multicolumn{3}{|c|}{------- m³ mº } & $\mathrm{kg} \mathrm{dm}^{-3}$ \\
\hline \multicolumn{5}{|c|}{ Araçatuba, safra 2011/12 } \\
\hline $0-0,05$ & 5,85 & 21,54 & 27,39 & 1,71 \\
\hline $0,05-0,20$ & 3,72 & 20,76 & 24,47 & 1,76 \\
\hline $0,20-0,40$ & 5,60 & 22,86 & 28,45 & 1,71 \\
\hline
\end{tabular}


Tabela 2. Teores médios de macroporosidade $(\mathrm{M})$, microporosidade $(\mu)$, porosidade total $(\mathrm{PT})$ e densidade do solo (DS), em diferentes profundidades, em Araçatuba, SP, safra 2011/12, e em Araçatuba, SP e Américo de Campos, SP, safra 2012/13.

(Conclusão)

Araçatuba, safra 2012/13

$\begin{array}{lllll}0-0,05 & 3,02 & 28,95 & 31,98 & 1,63 \\ 0,05-0,20 & 3,57 & 28,42 & 31,99 & 1,79 \\ 0,20-0,40 & 4,51 & 30,58 & 35,09 & 1,62\end{array}$

Américo de Campos, safra 2012/13

$\begin{array}{lllll}0-0,05 & 5,23 & 27,99 & 33,22 & 1,79 \\ 0,05-0,20 & 6,33 & 24,61 & 30,94 & 1,79 \\ 0,20-0,40 & 4,87 & 26,63 & 31,50 & 1,75\end{array}$

Figura 1. Penetrografia, Araçatuba, safra 2011/12.

Medição Média

\begin{tabular}{|l|c|}
\hline \multicolumn{2}{|c|}{ Atributos da Medicão } \\
\hline Hora & - \\
\hline Data & - \\
\hline Latitude & - \\
\hline Lonaitude & - \\
\hline Yino de Cone & $40 \mathrm{~cm}$ \\
\hline $\begin{array}{l}\text { Profundidade Máxima } \\
\text { Resolução da Medição } \\
\text { de Profundidade }\end{array}$ & $1 \mathrm{~cm}$ \\
\hline $\begin{array}{l}\text { Ocorrência de Excesso } \\
\text { de Velocidade }\end{array}$ & - \\
$\begin{array}{l}\text { Medição Completa (até } \\
\text { Prof. Máxima) }\end{array}$ & - \\
$\begin{array}{l}\text { Pressão Máxima } \\
\text { Prof. da Pressão } \\
\text { Máxima }\end{array}$ & $2240 \mathrm{kPa}$ \\
\hline
\end{tabular}

Média das Medicốes:

--Pasta 01: 29 Muediçốes.
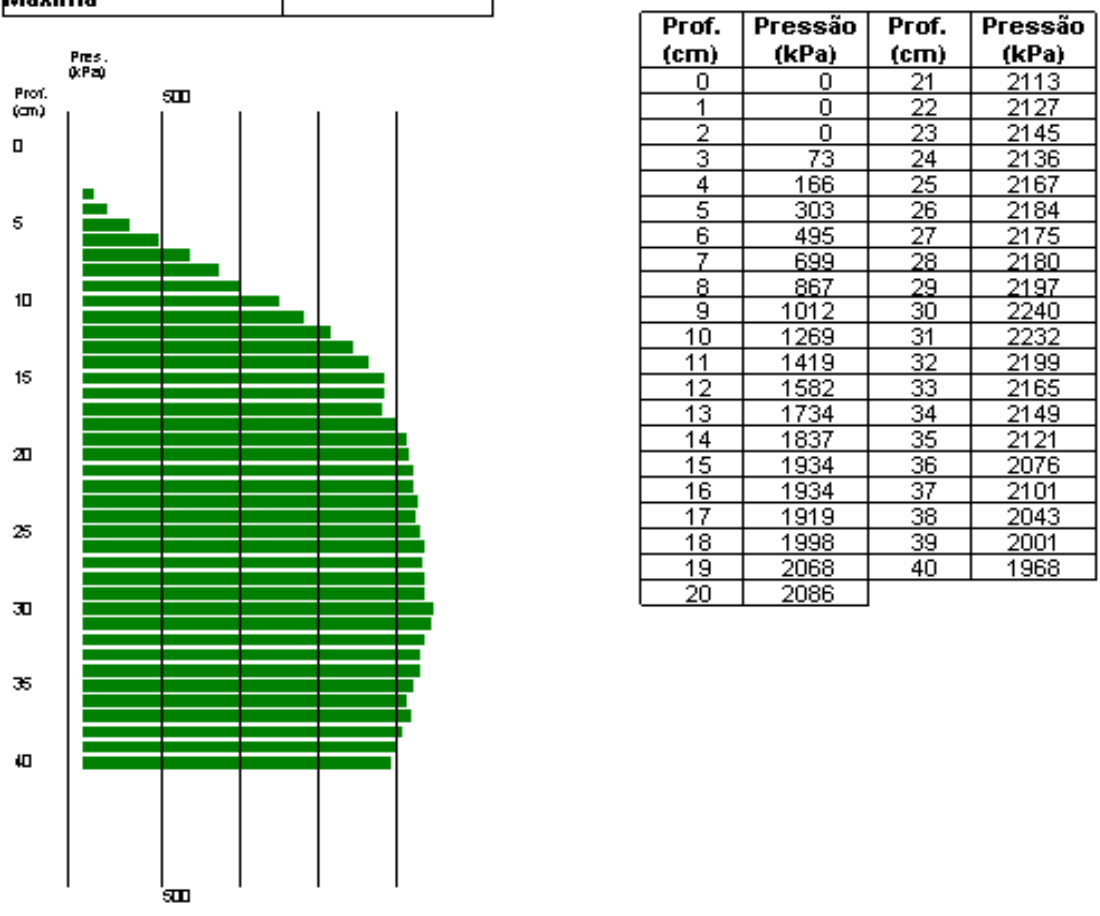
Figura 2. Penetrografia, Araçatuba, safra 2012/13.

\section{Medição Média}

\begin{tabular}{|l|c|}
\hline \multicolumn{2}{|c|}{ Atributos da Medição } \\
\hline Hora & - \\
\hline Data & - \\
\hline Latitude & - \\
\hline Longitude & - \\
\hline Tipo de Cone & $40 \mathrm{~cm}$ \\
\hline Profundidade Máxima & $1 \mathrm{~cm}$ \\
\hline $\begin{array}{l}\text { Resolução da Medição } \\
\text { de Profundidade }\end{array}$ & - \\
\hline $\begin{array}{l}\text { Ocorrència de Excesso } \\
\text { de Velocidade }\end{array}$ & - \\
\hline $\begin{array}{l}\text { Medição Completa (até } \\
\text { Prof. Máxima) }\end{array}$ & - \\
\hline Pressão Máxima & $3673 \mathrm{kPa}$ \\
\hline $\begin{array}{l}\text { Prof. da Pressāo } \\
\text { Máxima }\end{array}$ & $32 \mathrm{~cm}$ \\
\hline
\end{tabular}

Média das Mediçōes:

--Pasta 01 : 0112, 0116, 0119.

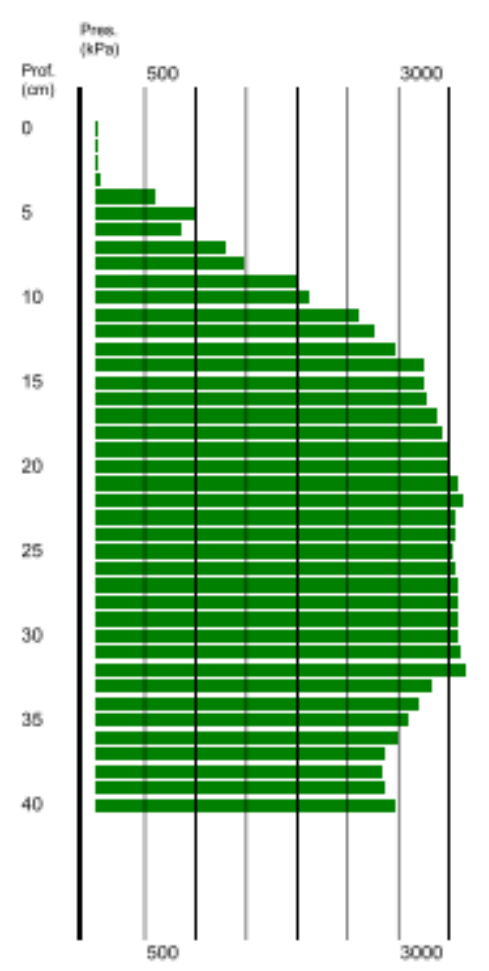

\begin{tabular}{|r|r|r|r|}
\hline $\begin{array}{c}\text { Prof. } \\
\text { (cm) }\end{array}$ & $\begin{array}{c}\text { Pressāo } \\
\text { (kPa) }\end{array}$ & $\begin{array}{c}\text { Prof. } \\
\text { (cm) }\end{array}$ & $\begin{array}{c}\text { Pressāo } \\
\text { (kPa) }\end{array}$ \\
\hline 0 & 0 & 21 & 3595 \\
\hline 1 & 0 & 22 & 3650 \\
\hline 2 & 0 & 23 & 3557 \\
\hline 3 & 67 & 24 & 3560 \\
\hline 4 & 585 & 25 & 3539 \\
\hline 5 & 997 & 26 & 3560 \\
\hline 6 & 868 & 27 & 3580 \\
\hline 7 & 1291 & 28 & 3583 \\
\hline 8 & 1471 & 29 & 3578 \\
\hline 9 & 1997 & 30 & 3598 \\
\hline 10 & 2131 & 31 & 3619 \\
\hline 11 & 2613 & 32 & 3673 \\
\hline 12 & 2758 & 33 & 3345 \\
\hline 13 & 2984 & 34 & 3219 \\
\hline 14 & 3245 & 35 & 3095 \\
\hline 15 & 3253 & 36 & 2990 \\
\hline 16 & 3302 & 37 & 2882 \\
\hline 17 & 3384 & 38 & 2848 \\
\hline 18 & 3423 & 39 & 2874 \\
\hline 19 & 3482 & 40 & 2964 \\
\hline 20 & 3518 & \multicolumn{2}{|l}{} \\
\cline { 1 - 2 } & & &
\end{tabular}

\begin{tabular}{|c|c|c|c|}
\hline $\begin{array}{c}\text { Intervalo } \\
\text { (cm) }\end{array}$ & $\begin{array}{c}\text { Pressāo } \\
\text { Média (kPa) }\end{array}$ & $\begin{array}{c}\text { Intervalo } \\
\text { (cm) }\end{array}$ & $\begin{array}{c}\text { Pressão } \\
\text { Média (kPa) }\end{array}$ \\
\hline 0 a 5 & 274,8 & 25 a 30 & 3579,8 \\
\hline 5 a 10 & 1551,6 & 30 a 35 & 3390,2 \\
\hline 10 a 15 & 2970,6 & 35 a 40 & 2911,6 \\
\hline 15 a 20 & 3421,8 & 0 a 40 & 2650,7 \\
\hline 20 a 25 & 3580,2 & \multicolumn{3}{|c}{} \\
\cline { 1 - 3 } &
\end{tabular}


Figura 3. Penetrografia, Américo de Campos, safra 2012/13.

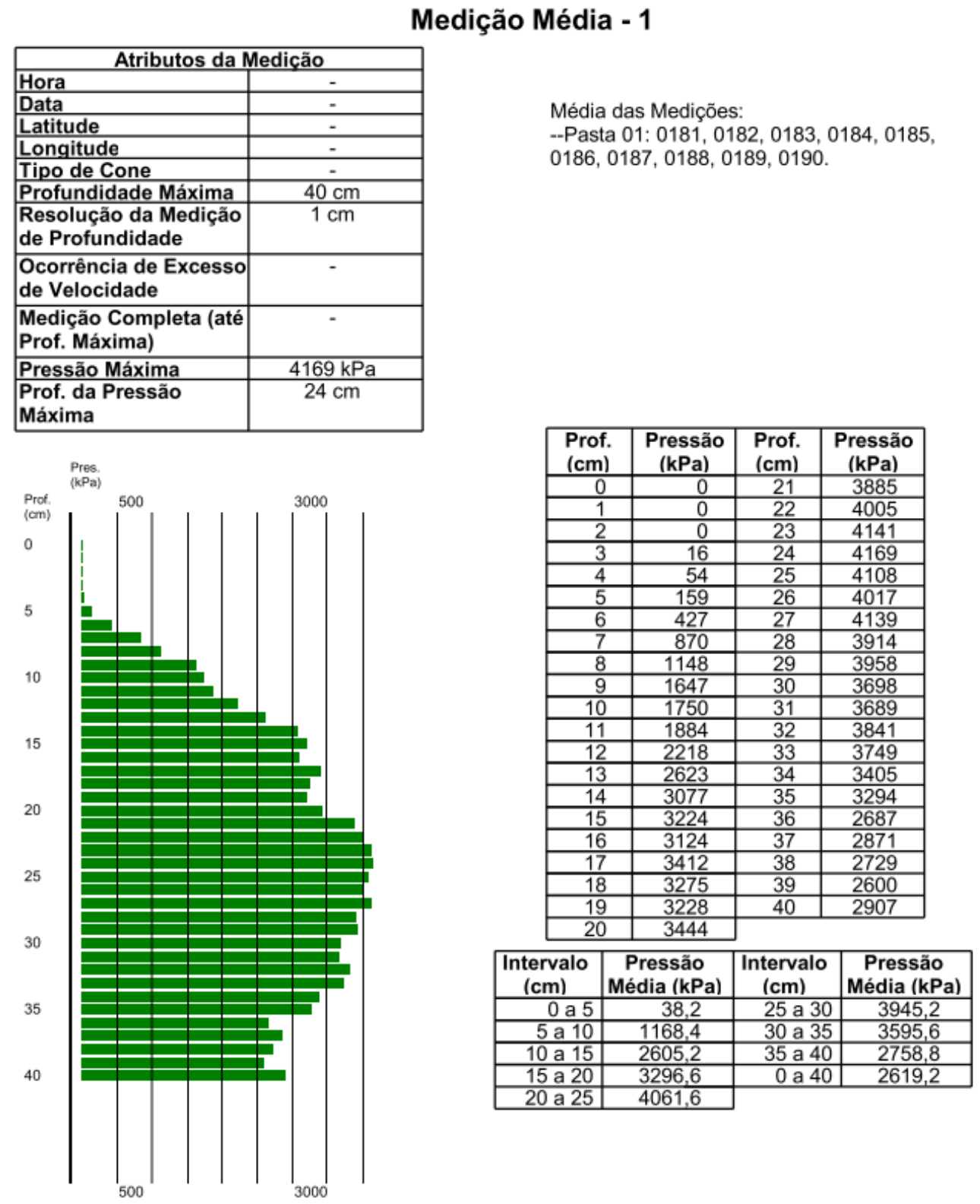

Os resultados da análise granulométrica, para a camada de 0,05-0,20 m, nos dois locais e nos dois anos de estudo, estão demonstrados na Tabela 3. 
Tabela 3. Análise granulométrica para a camada de 0,05-0,20 m, em Araçatuba, SP, safra 2011/12, e em Araçatuba, SP e Américo de Campos, safra 2012/13.

\begin{tabular}{lccc}
\hline Local/safra & Argila & Silte & Areia \\
& - & - & \\
\hline Araçatuba, SP - safra 2011/12 & 208 & 110 & 683 \\
Araçatuba, SP - safra 2012/13 & 180 & 62 & 758 \\
Américo de Campos - safra 2012/13 & 83 & 127 & 790 \\
\hline
\end{tabular}

A avaliação de fitomassa seca da palhada da cultura da cana-de-açúcar foi realizada no momento da semeadura, no florescimento e na colheita da soja, retirando-se três amostras por parcela de $0,25 \mathrm{~m}^{2}$ cada, em todas as parcelas, na safra 2011/12, e nas parcelas com as cultivares M-Soy 7908 RR e SYN 9078 RR, em Araçatuba, SP e Américo de Campos, SP, respectivamente, na safra 2012/13. Os resultados encontram-se na Tabela 4.

Tabela 4. Valores médios de fitomassa seca da palhada da cultura da cana-de-açúcar, no momento da semeadura, no florescimento e na colheita da cultura da soja, em Araçatuba, SP, safra 2011/12, e em Araçatuba, SP e Américo de Campos, safra 2012/13.

\begin{tabular}{lccc}
\hline Local/safra & Semeadura & Florescimento & Colheita \\
& & & \\
& & & \\
Araçatuba, SP - safra 2011/12 & 19036 & 18948 & 3380 \\
Araçatuba, SP - safra 2012/13 & 14450 & 11750 & 7626 \\
Américo de Campos - safra 2012/13 & 11200 & 7791 & 7517 \\
\hline
\end{tabular}

$\mathrm{Na}$ avaliação de fitomassa seca realizada no momento da semeadura, na safra 2012/13, após secagem e pesagem, as amostras foram encaminhadas ao laboratório de relação solo-planta, da Faculdade de Ciências Agrárias de Botucatu - FCA/UNESP, para avaliação dos teores de nitrogênio e carbono da palhada de cana-de-açúcar. Os resultados encontram-se na Tabela 5.

Tabela 5. Teores de nitrogênio e carbono da palhada de cana-de-açúcar em Araçatuba, SP e Américo de Campos, safra 2012/13.

\begin{tabular}{|c|c|c|}
\hline \multirow{2}{*}{ Local/safra } & Nitrogênio & Carbono \\
\hline & \multicolumn{2}{|c|}{------------------- g/kg ------------------- } \\
\hline Araçatuba, SP & 0,51 & 43,5 \\
\hline Américo de Campos, SP & 0,37 & 40,3 \\
\hline
\end{tabular}

Os parâmetros avaliados na cultura da soja foram: altura de inserção da primeira vagem, altura de plantas, estande final ha ${ }^{-1}$ e número de vagens por planta, amostrando-se cinco plantas de cada parcela e a produtividade de grãos ha ${ }^{-1}$, amostrando-se $10 \mathrm{~m}$ nas duas linhas centrais de cada parcela. As avaliações foram realizadas no momento da colheita. A produtividade foi obtida padronizando-se a umidade dos grãos para $13 \%$. 
Os dados foram submetidos ao teste $\mathrm{F}$ e realizado o teste de Tukey $(\mathrm{p}<0,05)$, para comparação das médias, com o uso do programa computacional ESTAT, desenvolvido pelo Departamento de Ciências Exatas da FCAV/UNESP/Jaboticabal (Estat, 1997).

Foram coletados dados mensais de pluviosidade e de temperatura média, em todo o período de execução dos ensaios. Os dados encontram-se nas Figuras 4 e 5.

Figura 4. Dados de precipitação pluvial (PP) e temperatura média (T), em Araçatuba, SP, no período estudado, outubro de 2011 a março de 2012 e novembro de 2012 a março de 2013. Fonte: CIIAGRO, 2013.

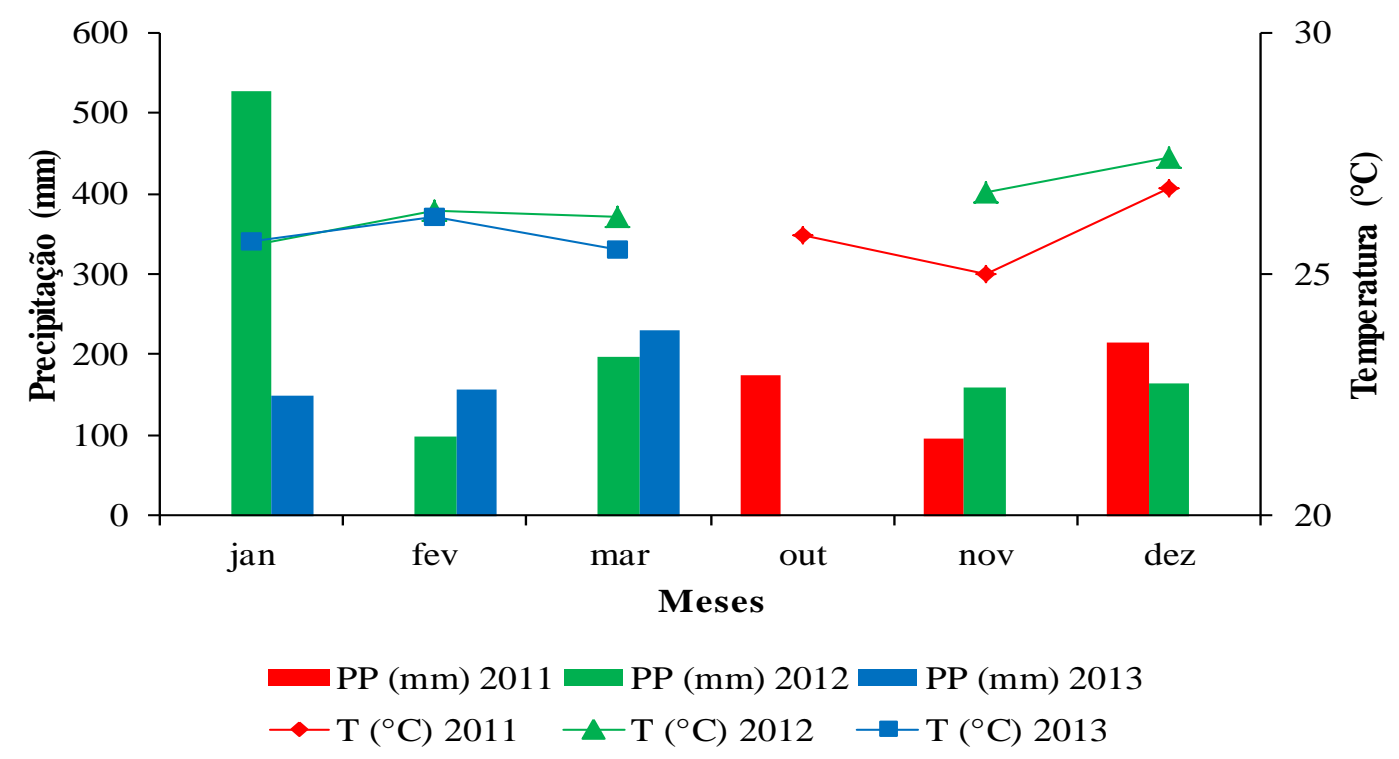

Figura 5. Dados de precipitação pluvial (PP) e temperatura média (T), em Paulo de Faria, SP (estação meteorologia mais próxima a Américo de campos, SP), no período estudado, dezembro de 2012 a março de 2013. Fonte: CIIAGRO, 2013.

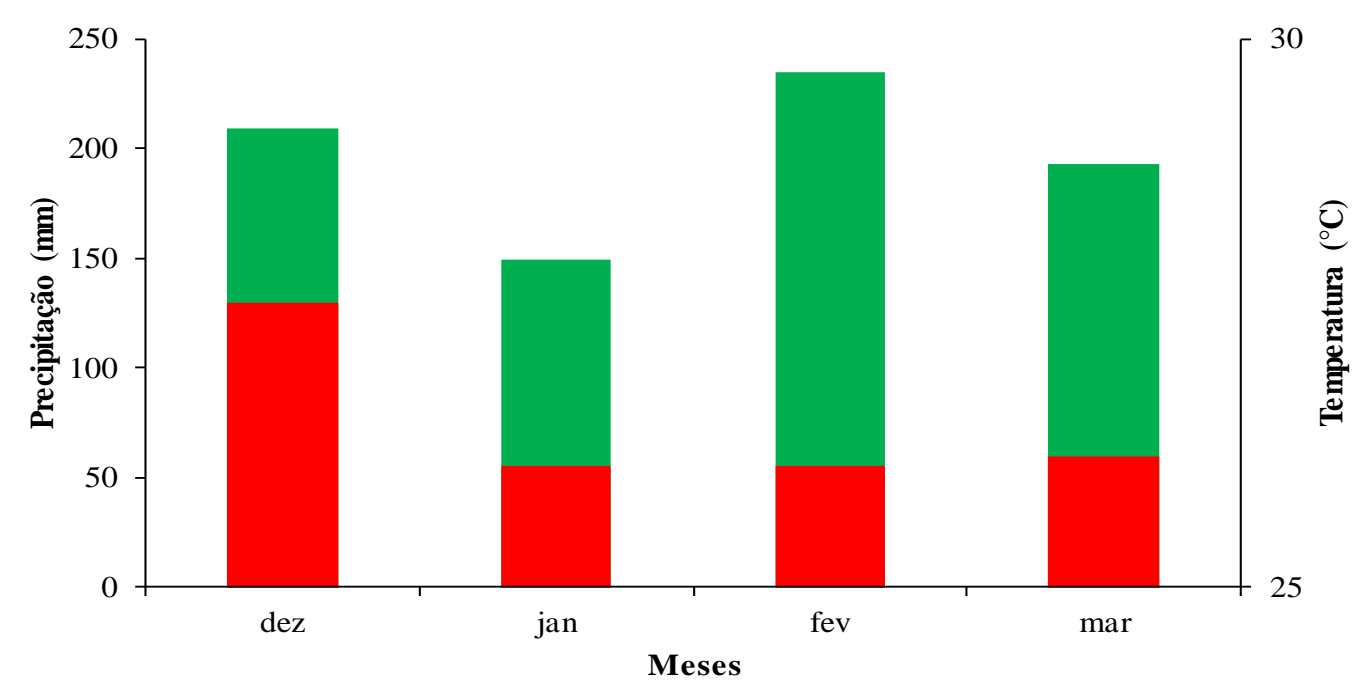

— PP (mm) 2012/13 — 


\section{RESULTADOS E DISCUSSÃO}

Na safra 2011/12, mesmo com o solo apresentando características físicas inadequadas para bom desenvolvimento da maioria das culturas, com porosidade total do solo, macro e microporosidade abaixo do ideal (Tabela 2) e resistência do solo a penetração superior a 2,0 MPa na camada de 0,19-0,39 m (Figura 1), a soja apresentou bom desenvolvimento vegetativo, com a cultivar SYN 9078 RR apresentando altura de plantas de $1,26 \mathrm{~m}$ e diferindo das demais, e boa produtividade de grãos, com a cultivar M-Soy $7908 \mathrm{RR}$, produzindo $4290 \mathrm{~kg} \mathrm{ha}^{-1}$ de grãos, superior a produtividade média nacional da cultura da soja, nas safras 2011/12, que foi de 2651 (CONAB, 2013), e diferindo das demais, conforme Tabela 6.

Tabela 6. Valores médios da altura de inserção da primeira vagem, altura de plantas, estande final, número de vagens por planta e produtividade de grãos de diferentes cultivares de soja, Araçatuba, SP, safra 2011/12.

\begin{tabular}{lccccc}
\hline Cultivar & $\begin{array}{c}\text { Altura de } \\
\text { inserção }(\mathrm{cm})\end{array}$ & $\begin{array}{c}\text { Altura de } \\
\text { plantas }(\mathrm{cm})\end{array}$ & $\begin{array}{c}\text { Estande } \\
\text { final ha }{ }^{-*^{*}}\end{array}$ & $\begin{array}{c}\text { Número de } \\
\text { vagens }\end{array}$ & $\begin{array}{c}\text { Produtividade } \\
\left(\mathrm{kg} \mathrm{ha}^{-1}\right)\end{array}$ \\
\hline M-Soy 7908 RR & 0,20 & $0,88 \mathrm{~b}$ & 248146 & 77 & $4290 \mathrm{a}$ \\
P 98Y11 RR & 0,23 & $0,89 \mathrm{~b}$ & 270368 & 88 & $2965 \mathrm{~b}$ \\
BRS Valiosa RR & 0,20 & $1,00 \mathrm{~b}$ & 230862 & 87 & $2635 \mathrm{~b}$ \\
CD 219 RR & 0,22 & $1,01 \mathrm{~b}$ & 255553 & 82 & $2613 \mathrm{~b}$ \\
SYN 9078 RR & 0,23 & $1,26 \mathrm{a}$ & 248146 & 73 & $2585 \mathrm{~b}$ \\
\hline DMS & 7,35 & 13,93 & 32 & 158,93 \\
\hline CV (\%) & 19,75 & 7,93 & 22 & 16,58 \\
\hline
\end{tabular}

Médias seguidas de mesma letra não diferem entre si pelo teste de Tukey a 5\% de probabilidade.

* Não se comparou as médias por variarem de acordo com a recomendação do detentor da cultivar.

Na safra 2012/13, apesar das características químicas e físicas do solo inadequadas para bom desenvolvimento da maioria das culturas, com presença de alumínio na camada de 0,20-0,40 m, nas duas localidades (Tabela 1), e porosidade total do solo, macro e microporosidade abaixo do ideal e densidade do solo acima do ideal, nas duas localidades (Tabela 2), e resistência do solo a penetração superior a 2,0 MPa a partir de 0,10 m, em Araçatuba, SP e a partir de 0,12 m, em Américo de Campos, SP (Figuras 2 e 3), a soja novamente apresentou bom desenvolvimento vegetativo, com produtividade média de grãos, entre todas as cultivares, nos dois locais, de $3409 \mathrm{~kg} \mathrm{ha}^{-1}$ (Tabelas 7 e 8), superior a produtividade média nacional da cultura da soja, na safra 2012/13, que foi de $2941 \mathrm{~kg} \mathrm{ha}^{-1}$ (dados estimados) (CONAB, 2013), mostrando ser a tecnologia da semeadura direta da cultura da soja sobre a palhada de cana-de-açúcar viável para a região em estudo.

No segundo ano de estudo as diferentes cultivares não diferiram entre si, a 5\% de probabilidade, quanto a produtividade de grãos, conforme Tabelas 7 e 8, corroborando com Bolonhezi et al. (2008), que também não encontraram diferenças entre as cultivares avaliadas.

Em relação a altura de plantas e altura de inserção da primeira vagem, a cultivar SYN 9078 RR apresentou a maior altura de plantas, nos dois locais, e a M-Soy 7908 RR a menor altura de inserção, em Américo de Campos, SP.

No momento da colheita da cultura da soja, realizada aos 113 dias após a semeadura, em Américo de Campos, SP, as cultivares BRS Valiosa RR e M-Soy 7908 RR apresentaram 23,5 e 16,5 \% de umidade, respectivamente, enquanto que as demais cultivares apresentaram umidade abaixo de $14 \%$, ideal para a 
colheita. Timossi e Durigan (2006) constataram que a cultivar M-Soy 6101 apresentou-se mais adequada para utilização dentro do período de renovação dos canaviais, pois atingiu o estádio R8 (colheita) nove dias antes, e citaram que essa antecipação torna-se importante no momento do planejamento da implantação do novo canavial.

Nos dois anos de estudo e nos dois locais, todas as cultivares apresentaram produtividade de grãos superiores as encontradas por Timossi e Durigan (2006), que foram de 2619,5 e 2513,2 kg ha-1, respectivamente, para as cultivares CD 206 e M-Soy 6101, em Jaboticabal, SP, na safra 2003/04, e a produtividade de grãos da cultivar M-Soy 7908 RR foi superior a encontrada por Bolonhezi et al. (2008), em Novais, SP, na safra 2007/08, que foi de $2050 \mathrm{~kg} \mathrm{ha}^{-1}$.

Tabela 7. Valores médios da altura de inserção da primeira vagem, altura de plantas, estande final e produtividade de grãos de diferentes cultivares de soja, safra 2012/13, Araçatuba, SP.

\begin{tabular}{lcccc}
\hline Cultivar & $\begin{array}{c}\text { Altura de } \\
\text { inserção }(\mathrm{m})\end{array}$ & $\begin{array}{c}\text { Altura de } \\
\text { plantas }(\mathrm{m})\end{array}$ & $\begin{array}{c}\text { Estande final } \\
\mathrm{ha}^{-{ }^{*}}\end{array}$ & $\begin{array}{c}\text { Produtividade (kg } \\
\left.\text { ha }^{-1}\right)\end{array}$ \\
\hline M-Soy 7908 RR & 0,12 & $0,65 \mathrm{bc}$ & 225183 & 3506 \\
BRS Valiosa RR & 0,15 & $0,75 \mathrm{ab}$ & 191109 & 3259 \\
SYN 9078 RR & 0,14 & $0,79 \mathrm{a}$ & 248146 & 3224 \\
P 98Y11 RR & 0,14 & $0,57 \mathrm{c}$ & 239257 & 2946 \\
NA 7490 RR & 0,14 & $0,66 \mathrm{bc}$ & 305923 & 2773 \\
\hline DMS & 0,0340 & 0,1029 & & 2404 \\
\hline CV $(\%)$ & 8,85 & 5,33 & \\
\hline
\end{tabular}

Médias seguidas de mesma letra nas colunas não diferem entre si pelo teste de Tukey a 5\%.

* Não se comparou as médias por variarem de acordo com a recomendação do detentor da cultivar.

Tabela 8. Valores médios da altura de inserção da primeira vagem, altura de plantas, estande final, número de vagens por planta e produtividade de grãos de diferentes cultivares de soja, safra 2012/13, Américo de Campos, SP.

\begin{tabular}{|c|c|c|c|c|c|}
\hline Cultivar & $\begin{array}{c}\text { Altura de } \\
\text { inserção (m) }\end{array}$ & $\begin{array}{c}\text { Altura de } \\
\text { plantas (m) }\end{array}$ & $\begin{array}{c}\text { Estande final } \\
\mathrm{ha}^{-1 *}\end{array}$ & $\begin{array}{c}\text { Número de } \\
\text { vagens }\end{array}$ & $\begin{array}{c}\text { Produtividade } \\
\qquad\left(\mathrm{kg} \mathrm{ha}^{-1}\right)\end{array}$ \\
\hline BRS Valiosa RR & $0,13 \quad \mathrm{a}$ & $0,56 \quad \mathrm{~b}$ & 299333 & 37 & 4174 \\
\hline NA 7490 RR & $0,11 \quad \mathrm{c}$ & $0,63 \mathrm{ab}$ & 269333 & 40 & 4023 \\
\hline P 98Y11 RR & $0,13 \mathrm{ab}$ & $0,58 \mathrm{ab}$ & 269333 & 34 & 3721 \\
\hline M-Soy 7908 RR & $0,08 \quad d$ & $0,45 \quad \mathrm{c}$ & 185333 & 59 & 3437 \\
\hline SYN 9078 RR & $0,11 \quad b c$ & $0,64 \quad \mathrm{a}$ & 272000 & 47 & 3022 \\
\hline DMS & 0,0174 & 0,0789 & & 42,1395 & 2885 \\
\hline $\mathrm{CV}(\%)$ & 5,40 & 4,89 & & 34,44 & 27,80 \\
\hline
\end{tabular}

Médias seguidas de mesma letra nas colunas não diferem entre si pelo teste de Tukey a 5\%.

* Não se comparou as médias por variarem de acordo com a recomendação do detentor da cultivar. 


\section{CONCLUSÃO}

As diferentes cultivares de soja avaliadas apresentaram bom desenvolvimento vegetativo e boas produtividades de grãos na Região Noroeste Paulista.

\section{AGRADECIMENTOS}

Agradecemos a Fundação Agrisus - Agricultura Sustentável, pelo apoio financeiro ao projeto que originou este trabalho, nas duas safras.

\section{REFERÊNCIAS}

ABRAMO FILHO, J.; MATSUOKA, S.; SPERANDIO, M. L.; RODRIGUES, R. C. D.; MARCHETTI, L. L. Resíduo da colheita mecanizada de cana crua. Álcool \& Açúcar, São Paulo, n.67, p.23-25, 1993.

BOLONHEZI, D.; FINOTO, E. L.; MONTEZUMA, M. C.; MICHELOTTO, M. D.; PAIVA, L. A.; QUEIROZ, F. C.; FERREIRA, J. A. H.; BELLUCCI, E.; MARTINS, A. L. M; FERNANDES, M. Plantio direto de cultivares de soja RR na renovação de cana em condição de Argissolo. In: REUNIÃO DE PESQUISA DE SOJA DA REGIÃO CENTRAL DO BRASIL, 30., 2008, Rio Verde. Resumos... Londrina: Embrapa Soja, 2008. p.45-47, 2008.

CANASAT. Mapeamento da cana via imagens de satélite. Disponível em: <http://www.dsr.inpe.br/laf/canasat/tabelas.html>. Acesso em: 23 maio 2013.

CIIAGRO - CENTRO INTEGRADO DE INFORMAÇÕES AGROMETEOROLÓGICAS. Resenha: Votuporanga no período de 01/11/2008 até 31/04/2010. São Paulo, 2013. Disponível em:

<http://www.ciiagro.sp.gov.br/ciiagroonline/Listagens/Resenha/LResenhaLocal.asp>. Acesso em 20 maio 2013.

CONAB - COMPANHIA NACIONAL DE ABASTECIMENTO. Séries históricas relativas às safras 1976/77 a 2012/2013 de área plantada, produtividade e produção. Brasília, DF, 2013. (Série histórica). Disponível em: HTTP://WWW.CONAB.GOV.BR/CONTEUDOS.PHP?A=1252\&T=\&PAGINA_OBJCMSCONTEUDOS=3\#A OBJCMSCONTEUDOS . Acesso em: 20 maio 2013.

ESTAT - Sistema para análises estatísticas. (V.2.0), Polo Computacional/Departamento de Ciências Exatas/UNESP-FCAV, Jaboticabal, [s.d.]. 1997.

FINOTO, E. L.; BOLONHEZI, D.; SOARES, M. B. B; MARTINS, A. L. M. Produção de soja RR e ocorrência de plantas daninhas em áreas de reforma de cana crua com diferentes manejos na destruição da soqueira. Pesquisa \& Tecnologia, v. 9, n. 2, 2012.

KUVA, M. A. Banco de sementes, fluxo de emergência e fitossociologia de comunidade de plantas daninhas em agroecossistema de cana. 2006. 105 f. Tese (Doutorado em Agronomia) - Faculdade de Ciências Agrárias e Veterinárias, Universidade Estadual Paulista, Jaboticabal.

NOGUEIRA, G. A. Plantio De Soja Em Área De Renovação Com Palha Residual De Colheita Mecanizada De Cana Crua. TrabalhosFeitos.com. 09 2012. Disponível em: <http://www.trabalhosfeitos.com/ensaios/Plantio-De-Soja-Em-Área-De/351247.html>. Acesso em 22 maio 2012.

PAREDES JUNIOR, F. P. Bioindicadores de qualidade do solo em cultivos de cana-de-açúcar sob diferentes manejos. 2012. 95 f. Dissertação (Mestrado em Agronomia) - Universidade Estadual de Mato Grosso do Sul, Aquidauana. 
SOUZA, Z. M.; PRADO, R. M.; PAIXÃO, A. C. S.; CESARIN, L. G. Sistemas de colheita e manejo da palhada de cana-de-açúcar. Pesquisa Agropecuária Brasileira, v. 40, n. 3, p. 271-278, 2005.

STABEN, M. L.; BEZDICEK, D. F.; SMITH, J. L.; FAUCI, M. F. Assentement of soil quality in conservation reserve program and wheat-fallow soils. Soil Science Society of America Journal, v. 61, p. 124-130, 1997.

TASSO JUNIOR. L. C. Plantio direto de culturas de verão - Revista do Agricultor, p. 12-13, 2000.

TIMOSSI, P. C.; DURIGAN, J. C. Manejo de convolvuláceas em dois cultivares de soja semeada diretamente sob palha residual de cana crua. Planta Daninha, Viçosa, v. 24, n. 1, p. 91-98, 2006.

TRIVELIN, P. C. O.; RODRIGUÊS, J. C. S.; VICTORIA, R. L. Utilização por soqueira de cana-deaçúcar de início de safra do nitrogênio da aquamônia-15N e uréia-15N aplicado ao solo em complemento à vinhaça. Pesquisa Agropecuária Brasileira, v. 31, p. 89-99, 1996. 
